\title{
Designing for Player Experience How Professional Game Developers Communicate Design Visions
}

\author{
Ulf Hagen \\ Södertörns University \\ 14189 Huddinge, Sweden \\ ulf.hagen@sh.se
}

\begin{abstract}
This paper investigates the prevalence of deliberate design for player experience in big game studios, and how potential visions of intended player experience are articulated and communicated to the team in the course of the development process. The primary data consist of interviews with six Swedish game developers. The study shows that the practice of designing for player experience is indeed in use by many game developers, and that a wide variety of tools are employed to articulate and communicate their visions. The main purpose of this communication is to allow everyone in the development team to make design choices that are in line with the commonly shared design vision.
\end{abstract}

\section{Keywords}

Game design, experience design, player experience, design practice, design tools

\section{INTRODUCTION}

Welcome to the Experience Economy is the title of an article published in the Harvard Business Review, July 1998. [17] In the article, Pine and Gilmore state that experience is the new economic value. The focus on experience is notable in many fields of human activity, for example, the "experience industry", "experience tourism”, “experiential learning” and "experience design”. During the last decade, an increasing interest in experience has also emerged in the fields of humancomputer interaction and interaction design, both among academics and professional designers. In 2004, two books were published that had great impact; Donald Norman's Emotional design: why we love (or hate) everyday things [15] and John McCarthy \& Peter Wright's Technology as experience [12]. The latter was inspired by Dewey's Art as experience from 1934 [5]. $\mathrm{CHI}$, the premier international conference for humancomputer interaction, have a "community" dedicated to user experience, and in addition to the initial focus on function (usability), experience (look and feel) have become an important design goal, e.g. in web design practice [13].

Creating artifacts for user experience is not a new idea, of course. Most works of art, whether literature, music,

Nordic DiGRA 2010. DiGRA (c) 2010 Authors \& Digital Games Research Association (DiGRA). Personal and educational classroom use of this paper is allowed, commercial use requires specific permission from the author. fine art or film, aim to bring the audience various kinds of experience; amusement parks are built with the same intention. The same goes for games. The purpose of games has always been to be fun, entertaining and enjoyable.

If artists always have tried to give their audience an experience and if software developers design for user experience nowadays, then it's not far-fetched to assume that game developers also may benefit from using experience design in the game design process. A contemporary video game could be seen as a mixture of software engineering and artistic creativity.

In game design, a new game concept can be approached from many angles. One way to get to the-game-to-be is to describe the different elements of the game itself; the features, the core mechanics, the rules, the setting, the characters, the story, and so on [8]. This approach focuses on the game as an artifact. Another way is to give attention to the player of the game, with notions of the experience that the player should have while playing the game. I will call this approach designing for player experience.

In this paper, I report a study of actual design practices among a number of game developers. The study can be divided into three parts. In the first part I investigate if the approach "designing for player experience" is commonly used as a practice among today's game developers.

Secondly, since experience is a subjective and complex phenomena, it is very hard to predict what experience a certain player will have while playing a game, thus in the second part of the study I try to find out how game designers solve this problem, if they want do design for player experience.

Thirdly, many video games are created by large teams of people with different roles in the production process. Since the creation of a game is a collective task, it's important that everyone in the team is familiar with the game concept and share the same vision about the final product. In the third part of the study I investigate how game developers express or articulate the vision about the experience they want to convey through the game, and how they communicate the vision to the development team and other stakeholders.

In other words, my focus in this study is to study and describe game design practices used in design for player 
experience. With this I mean design practices where the focus is on intended player experience.

"Experience" is a philosophically complicated concept, hard to define [2]. In this paper I have avoided this problem, since I study game developers' design-related usage of what they refer to as "experience". Besides the word experience I have also taken into account when a developer describe a game and gameplay with words like fun, feeling, scary, atmosphere, feel, immersion, presence, satisfaction, having a good time etc. These words also refer to the player's inner life and are therefore, like experience, not simple components that mechanically can be built into the game.

\section{Previous studies}

I haven't found any studies on actual design for player experience as practiced in professional game studios. The literature on design for player experience as a method is also very limited. Some of the recently published handbooks in game design mention the design for player experience approach $[1,19,21]$, and there are also a few articles that discuss the subject [11, 22].

When it comes to player experience, there is much more written. Both scholars $[3,4,6,7,9,14]$ and authors of handbooks $[1,18]$ have tried to analyze, categorize and theorize player experience in different ways.

In the fields of human-computer interaction and interaction design there is plenty of research on user experience and user experience design. See $[10,16]$ for an orientation.

\section{Method}

I have used a qualitative approach that included different data collection techniques. My primary data come from interviews with six game designers, representing the five major game development studios in Sweden:

$\begin{array}{lll}\text { Interview date } & \text { Respondent's role } & \text { Studio } \\ \text { 2009 May 15 } & \text { Executive Producer } & \text { Grin } \\ \text { 2009 May 21 } & \text { Lead Designer } & \text { Massive } \\ \text { 2009 May 27 } & \text { Senior Producer } & \text { Dice } \\ \text { 2009 June 4 } & \text { Game Designer } & \text { Avalanche } \\ \text { 2010 February 24 } & \text { Lead Designer } & \text { Dice } \\ \text { 2010 February 25 } & \text { Game Director } & \text { Starbreeze }\end{array}$

The six interviews lasted about one hour each, and was tape recorded, with the consent of the respondents and then transcribed for analysis.

My interviews were semi-structured and the questions concerned game design and game development in general. I used a grounded theory approach, as I wanted to learn about design practices in big game studios without preconceptions. Therefore, in the first four interviews, I did not ask any specific questions about designing for player experience, but the more data I got, the more I realized that this was an important design practice among my respondents.

Apart from my own interviews I have used some secondary data from interviews with game developers made by others (available on the web), and from game designers' articles and recorded talks at conferences.
In the next section, I will give several examples of how game designers talk about designing for player experience. I have deliberately chosen to include rather long quotes, because I think it is significant to see how they describe the design process, especially how they express themselves when they talk about their design for player experience.

\section{DESIGNING FOR PLAYER EXPERIENCE}

When asked about game design in general, all my respondents brought up player experience as an important focus in their game design.

\section{The Senior Producer at DICE said:}

All studios have their own methods for coming up with what the game is. We usually think quite... how should I put it... naïvely. You close your eyes and think: What do I find fun? It's as simple as that. [...] An example in Bad Company was that we focused quite much on what we call destruction... that you can shoot holes in walls, you can knock down trees, and you can... you can act quite badly! And that was the result of contemplating about: What did you find fun when you were a kid? $[\ldots]$

So, we base it on very basic feelings. It's fun to destroy. Unfortunately. People in general think it’s fun to destroy things. If they get the opportunity to destroy something without negative consequences, they gladly do it.

He also explained how ideas of intended player experience would guide the pre-production phase:

....and then you build the game upon that [that it's fun to destroy]. But you can do it in many different ways. We have this good Swedish engineering tradition, so we don't want to do something that feels trivial and boring - it should be done properly! So, of course, we put a lot of energy [into that]... The idea in itself is very simple. Anyone can come up with that idea; you don't have to be a genius to do that. The hard part is to create... to refine it and develop it into something that is actually fun to play. Imagine playing a game where everything is possible to destroy, and then you destroy everything and then everything is flat. You run around on flat ground. That's not very fun. [...]

No, so for us, it is all about finding the balance between the different elements and making it feel fun, believable and exciting.

The lead designer at Massive explained why it is important to find out early if the game is fun to play.

You ask yourself: "What kind of drama should it be... what feeling do you want to bring out?" The design documents you create today are very light stuff. It's more a presentation, a thought, it mustn't be a structured document... it could very well be a power point $[\ldots]$

And then the game itself... it's very physical. You should be able to play it... you develop it by prototyping it, so you don't take any chances... Earlier, you wrote a 300 page design document and then you thought "this will be really fun... later". But 50 percent of what you write... isn't useful, because it's just a product of the drawing board, you know. [...] 
This is a new vibe in the games industry [...] I would say that it began, maybe three years ago [i.e. 2006]. But it's not until now that people talk about it at game conferences and expos in another way.

Taking the hunting game The Hunter as an example, the lead designer at Avalanche also emphasized the benefit of working with player experiences, like pace and atmosphere, when designing a game:

We focused on making it as realistic as possible, and on slowing down the pace in the game, and it seems to have paid off. If you read the forum [...] everyone is very pleased that it [the game] is so different [...] it usually makes no difference what hunting game you take home, because they are all more or less the same, and none of them puts much focus on the atmosphere. So that was the right decision.

He also explains how the aim for realism affected the design of the player experience and the gameplay:

How did we do this? [...] our thought was: Okay, if we think backwards then... If what you do least in the game is to actually shoot at things, doesn't it become a more rewarding thing to really do it then? I mean, we can draw a parallel here: We think Shadow of the Colossus here... [...] to bring down one of those colossuses in that game is a pretty big undertaking... and the feeling here was kind of... we will go a bit in that direction: when you finally catch sight on an animal, you should be nervous, you should be trembling, sort of... it should be scary because if you miss this shot and scare this deer away, he will run away and you will have to take up the track again.

Okay, but it can't be just about walking around aimlessly, sort of... it's not enough just to lower the animal density, it can't be that simple... well, maybe you might achieve the goal to some extent, but in that case you would force the player to direct his/her own experience. So what we chose to make gameplay of is the actual tracking of the animals. That's the main thing, which distinguishes The Hunter from other hunting games.

\section{Autobiographical Design}

But, assuming that design for player experience is useful, how do you find out what are desirable player experiences? As told earlier, the senior producer at Dice suggested: "You close your eyes and think: What do I find fun? It's as simple as that."

The lead designer at Massive also stressed that it is the designer's own personality and enthusiasm that forms the game. He talked about the "vision bearer", that could be a single person, but more often a small team:

We talk very much about the core team, which is the team that really pushes the game forward, that makes the essence of it... it's so extremely important what combination of people it has, because it affects what kind of game it will be. You need a specific combination of people to be able to make a certain kind of game. If you are going to make a game like Tetris, perhaps you don't need a dramaturge. You should have someone who loves to play with Rubik's Cube and can engage with those parts. So it's very much the composition of the group that defines what kind of game we are working on.

For a scholar in the field of human-computer interaction, this probably sounds like a very subjective and unscientific way to find out what the future players of a game would appreciate. There are, after all, lots of research about user experience and player experience that ought to be useful here. However, in her paper Autobiographical Design [20], Sengers argues that what she calls "autobiographical design” (design with respect to details of its designer's personal experiences) could be appropriate in certain circumstances, namely:

- when there is a specific aspect of his or her own personal experience which the designer would like to offer to his or her target audience;

- when there are reasons why the target audience may be interested in that piece of experience; and

- when the designer has thought through carefully how his or her own experiences may be useful for or taken up by the target audience

If we compare this to the creative work of an artist (e.g. an author or a painter) the first criterion would probably be regarded as sufficient to justify the autobiographical approach. In so called fine culture, adjustments to a potential audience are usually frowned upon, but in the commercial entertainment industry the conditions are of course different.

Commercial game projects are typically financed by publishers, and they expect the game to be profitable. Developers who want to design their own game concept (or "IP", intellectual property) have to sell in or "pitch" the idea to a publisher, before they can get any money, and they usually have to get a "green light" at different points in the development process to get more money for the next phase. This way there are economic incitements, forcing the developers to adjust their game to what they (and their publisher) think will be appreciated by the customers, i.e. the potential players of the game.

It is also very common that the publisher asks the developer to make a game of an existing IP or to make a sequel to an old game. In those cases the creative scope is more limited, but the developer still needs to make design choices within the boundaries set by the IP itself or by the publisher. Since it's not the designer's own initial idea, it could be harder to use autobiographical design, though. The game designer at Avalanche described how he solved this, when working with the hunting game he had been asked to design:

When I approached the task, I started to think a little, and I thought: wait, I don't play hunting games... I don't know what they are all about... but, if I reflect on what hunting is like, and what I associate with hunting, I might have a starting point to work from... I sat there thinking... what is interesting when it comes to hunting? How does it feel if I imagine that picture of someone, who is going to pot a deer in the forest? What frame of reference do I have? And so on... 
And then I was thinking... well, it should be something like... much focus on stealth and things like that... yeah, okay... and I got some ideas... so I thought I should play some other hunting games... and so I did... and it turned out that not a single one of those hunting games was even close to... or did even try to create that feeling that I associated with hunting. No one had even made an effort to [think] "now we will try to bring about a nice stealth-feeling, now we will sneak through the bushes, it should take a long time..."

This story shows that it is not always bad to be unfamiliar with genre conventions and other stereotypic concepts, when you are designing games. But what you need to be familiar with is human psychology. The lead designer at Massive described what the creative process might look like, when using autobiographical design for player experience combined with some general knowledge about human psychology:

Let's take a game that is about water for instance. Then you can think: okay, why do we want to make a water game? Why would we want to do something with water at all? What's the underlying... what is it that we want the player to feel?

Well, okay, what can you... what is awesome about water? Claustrophobia... dynamic, it's kind of... it can leak in everywhere... you can't really control it, you know. So maybe you start working with those feelings... so you put down something like that, and you start trying to find scenarios we can use to bring out those feelings. Claustrophobia [...] is something everyone can relate to... and then you know you're on the track of something good. [...]

So [...] we've had brainstorming, we have decided that we want to do a game about claustrophobia, for instance... it should be the main theme in the game. Then you can start to specify a number of scenarios... and I would prefer then, to have a person... to work with an artist, who could sketch up different scenarios, so that everyone can understand. Because communication is the most important... to make the others grasp the vision bearer's idea is almost the most important thing to work on. So if you want to create a complicated movement pattern, that the player is supposed to follow, well, then you might want to make a small short film... so you don't have to write any code... instead you make a little film with simple prototyping tools, so that when everyone sees the film they go: oh, so that's what we're supposed to recreate... so that the programmers understand what it is you want them to do with the character. That's much better than a 300 pages long text document, where you say that you want to do this and that...

Besides describing how important it is that the team is composed of the right kind of people, the last part of the description above also stresses the need for communication. In the next section, I will elaborate on this and give a wide variety of examples of how game developers go about explaining and communicating their vision of the game-to-be.

\section{COMMUNICATING THE DESIGN VISION}

The size of a developing team in a big game production varies a lot during the different phases in the development process. During the concept phase there is seldom more than 10 people in the team, and in the preproduction phase the team grows to 20-30 members. When production starts more people are needed for the content creation, so then the team typically grows to around 100-200 people. Finally, the number of people declines again in the final phase, when quality assurance, testing and distribution of the game take place. The game's high-level ideas, the core concept and the overall vision are normally articulated during the first two phases (the concept phase and the pre-production phase), but that does not mean that there is no need for creativity and design choices later in the process. In the production phase, when the team reaches its peak number of members, most of the content (assets) of the game is produced, and even if the fundamental outlines are fixed, there is always room for creativity in details, like the visual appearance of characters and objects in the game.

All of my six respondents strongly emphasized the importance of communicating the design vision to all of the team members. The lead designer at Dice explained why this is important:

The best work actually happens when people are allowed to be creative within the boundaries that you have set up. Then you can sometimes see things that surprise you: "oh, that was a smart use of that thing", for instance. [...] I think it's good if as many as possible feel that they are a part of the process when developing a game, that they all are game developers.

Or, as the senior producer at Dice expressed it: "I don't want just their hands, I want their brains too”.

But, continuous idea generation from many different people can also be a problem, as explained by the former game designer Paul Tozour:

Everyone wants to have their voice heard, and everyone wants to contribute to the design. Everyone is full of ideas, and a lot of them are necessary to finish the game - many of the best ideas come from artists and engineers. Designers can't do it alone. [...]

But there is a catch, according to Tozour:

Brainstorming is a good way to light a creative spark, but it's not a good way to do game design. Design is less about finding a hundred great ideas than finding ten good ideas that work together in a cohesive and harmonious whole, as a solid and focused player experience. $^{1}$

So how do you solve this dilemma? In my study I found that there are wide varieties of practices that help game developing teams to evaluate and choose between different ideas. The overall guideline is to know what kind of game you are developing - you have to define the vision of the game in a way that everyone in the team can understand and assimilate. In the following section, I will give examples of different ways to express and

\footnotetext{
${ }^{1}$ Tozour, Paul (2009) The Long Road to Mordor, blog post in the Game/AI blog, January 29, 2009. http://www.ai-blog.net/archives/000157.html. [201005-04]
} 
communicate the design vision of a game, and I label them in order to create a tentative typology. I have used two criteria when selecting the examples; they must either be about the intended player experience itself or about components of the game-to-be that are supposed to affect the player experience.

\section{Verbal Ways to Express the Design vision}

The traditional way to define the design vision of a game is to write a game design document (GDD). This is in line with old software engineering tradition and the so called waterfall method that is not used so much anymore, according to my respondents. As mentioned earlier, the GDD is nowadays considered too comprehensive, which means that nobody bothers to read it. For the purpose of expressing and communicating the design vision of the game, the game developers have found other tools.

\section{Concise and Expressive Descriptions}

One way to express the design vision of a game is to find words and phrases that capture the idea in a nutshell, without using long and time-consuming descriptions. A popular name for a short and snappy description is the "elevator pitch". It's a way to describe the game concept in the time span of a short elevator ride.

According to the game director at Starbreeze: "The pitch is often based on other games... so, you say something like this: 'Imagine Knights of the Temple and Riddick... but cartoony!"”

But the description could be even shorter, sometimes even just one word. Indie game designer Kyle Gabler uses the word "juicy" to express the sensual feeling that he and Ron Carmel was aiming for, when they were developing the game World of Goo:

Make it Juicy!

"Juice" was our wet little term for constant and bountiful user feedback. A juicy game element will bounce and wiggle and squirt and make a little noise when you touch it. A juicy game feels alive and responds to everything you do - tons of cascading action and response for minimal user input. It makes the player feel powerful and in control of the world, and it coaches them through the rules of the game by constantly letting them know on a per-interaction basis how they are doing. ${ }^{2}$

\section{Key Areas of Focus}

In a talk at the Game Developers Conference (GDC) 2009, the lead animator and the lead programmer of the game Mirror's Edge described the four key areas of focus ("KAOF's") that they had used to communicate the design vision of the game. One of those KAOF's is especially interesting from the viewpoint of this paper,

${ }^{2}$ Gabler, K. et.al. (2005), How to Prototype a Game in Under 7 Days, part 4: General Gameplay: Sensual Lessons in Juicy Fun, in Gamasutra: Features, October 26, 2005.

http://www.gamasutra.com/features/20051026/gabler_0 3.shtml [2010-05-05]. because it tries to clearly verbalize the intended player experience:

"Through the character experience" is probably the most important of the four, 'cause it sums up the whole focus of the game. In our Battlefield games we had been using an expression called "through the gun experience", to describe how the game should feel. And by that we meant that the player should feel present on the battlefield through his weapon, and kind of feel the trigger and recoil and the bullet flying through the air. In Mirror's Edge, the focus was a different one. It was more about the body and movement, and less about weapon and fighting. We wanted to create a feeling of immersion in the world and in the character. So we wanted the player to feel each movement, feel the height, when on a high rooftop and the satisfaction of defying death with a perfectly timed jump... and to feel the ledge when you grab on to it, and so on. So we came up with "through the character experience" and it became sort of a mantra for us, and a frame of reference, when discussing features and ideas for the game, so we could question ourselves if it actually brought something to the "through the character experience". ${ }^{3}$

Later in the talk they also gave an example of the impact that the expression "Through the character experience" had had on the development. Since they wanted the player to really feel like s/he was inside the player character (a woman called Faith), they had to invent new ways to animate the movements of the character to make them more realistic than in other first person games. In earlier first person games the movements were usually very stiff and straight, as if the virtual camera were placed on a rail vehicle. First, they tried to put the virtual camera on Faith's head when she was running and jumping, but that didn't work because it became too bumpy and people felt moving sickness when playing. (In real life we perceive our own movements as smooth and stable, because the bumpiness is eliminated by our brain.) The team realized they had to animate the movements as we perceive them in real life, not as they objectively are. This was only possible to do by hand, using trial and error until it felt realistic. This was very time-consuming, of course, but since it was a key area of focus to make a "through the character" experience, it was justified to put that much effort into it.

\section{The One Question}

Harmonix, the studio that developed Guitar Hero and Rock Band, converts the design vision into a question, in order to use it as a tool for making design choices. They call it "The One Question". When they developed Guitar Hero they used "Does it rock?" as "The One Question" and for Rock Band it was "Is this an authentic band experience?"

Dan Teasdale, Rock Band's senior designer, explained the purpose of "The One Question" in a talk at the Game Developers Conference (GDC) 2009:

\footnotetext{
3 Åberg, J., \& Dahl, T. (2009). Creating First Person Movement for Mirror's Edge. GDC Proceedings: March 23-27, 2009. Moscone Center, San Francisco.
} 
I needed to get everyone to have the exact same design direction in their heads when making the game. [...]

Basically, whenever you're asking yourself questions about focus or scope or direction or content, you ask yourself “The One Question”. So if you do it right, you instantly have the entire team making the same types of judgement calls. ${ }^{4}$

By asking: "Is this an authentic band experience?" the development team could decide what ideas they should implement in the game or what ideas they should dismiss. The gameplay feature that gives band members the option of saving a friend who has been kicked out of the game because s/he didn't play well enough was, for example, implemented in the game. It was considered authentic because the members of a band usually help each other if they get in trouble on stage. On the other hand the idea of "power-ups" was dismissed, because, according to Teasdale: "they totally break the whole authentic band feel, like capturing all of my notes on track doesn't feel like an authentic band experience”.

\section{Similes and Exemplars}

Many descriptions of sought player experience have the following form: "The player experience should be similar to the experience you have when...” The exemplar could be a feeling experienced in another game, in a movie or a book etc, but it could also be an activity in real life that everyone is familiar with. The senior designer at Dice said, for example, that the experience Dice wants to give the player in all the Battlefield games is not the feeling of real war, but the feeling you had when you where a kid and played war, "Cowboys and Indians" or paint ball.

This is similar to the example given by the lead designer at Avalanche (see above) when he described how he let himself be inspired by a real-life hunting experience when designing The Hunter.

A third example is the reason why the lights in the survival horror game Dead Space look like dentists' lights. Ian Milham, the art director of the game explained why, in a talk at the GDC 2009: "We tried to think of real-world situations where you were uncomfortable and not having a good time - and the dentist's chair is one of the chief ones..." 5

\section{Anti-exemplars}

Another way to characterize the player experience is to refer to something that is the contrary to the experience you are aiming for. Then the typical from of the description is: "The player experience should be the opposite of the experience you have when... ". The lead designer at Avalanche used the game Duck Hunt as an anti-exemplar, when he was designing The Hunter. In Duck Hunt ducks (and clay pigeons) regularly appear on the screen, without any player effort. This experience is

4 Teasdale, D., Dirty Deeds Done Dirt Cheap: Design Lessons Learned from Rock Band. GDC Proceedings: March 23-27, 2009. Moscone Center, San Francisco.

${ }^{5}$ Milham, I., Art Directing Horror and Immersion in Dead Space. GDC Proceedings: March 23-27, 2009. Moscone Center, San Francisco. opposite to the one he wanted to achieve in The Hunter, where the player has to work hard to track the animals before getting a chance to shoot them.

During the development of the survival horror game Dead Space, the art director formulated three "keys to horror art direction" to make sure that the art in the game should intensify the horror experience for the player. One of the keys was "Must move away from Sci-fi action!" The reason behind this anti-exemplar is that science fiction action games like Halo and Mass Effect seldom are experienced as horrifying in the way survival horror games are supposed to, and since Dead Space takes place in a spaceship in the future, there was a potential risk that the art team unconsciously would be influenced by the science fiction action genre.

\section{Non-Verbal Ways to Communicate the Design vision \\ Concept Art}

The most common way to express the "look and feel" of the game is to use concept art. The executive producer at Grin explained how it can be used, when you just want to capture a feeling or mood:

You sketch it up fast... you can't discern much in the image, but you get the feeling, the visual feeling... and then... What kind of mood will the player be in, here? [...] It's dark, futuristic, anxiety or whatever you want.

\section{Existing pictures and mood boards}

But you can also use existing pictures for inspiration and as exemplars or anti-exemplars. To explain the sciencefiction anti-exemplar mentioned earlier, the art director of Dead Space used a collage with snapshots from movies, to make his team understand important visual differences between horror and science fiction. In his talk at the GDC 2009 he described the collage like this:

You can see that the horror stuff tends to have a warm, ochre, decayed sort of tones, high contrast sort of setups, compared to the sci-fi stuff: you tend to get cooler stuff, you get brighter hot spots, you get specularity and all kinds of stuff that show off graphical hardware that your marketing team wants you to put in the game... but it doesn't really jive with... that kind of visual excitement doesn't really jive with the horror feeling.

\section{Moving Images}

Animations and videos are impressive tools for mediating both the game play and the atmosphere in the game-tobe. As with still pictures, the team can produce their own movies or use existing ones. The lead designer at Dice gives an example of the former from the Mirror's Edge development:

We made a... kind of... mock-up animation, that's the playblast, where she runs after the stuff... jumps backwards over something, shoots at some cops... jumps between two rooftops... runs down a staircase... goes down to the street on a zip-line, and runs around. These kinds of things are very, very good for making people understand what you're trying to build.

In the GDC talk mentioned earlier, Dan Teasdale described how a rock concert video from the 70's with The Who served as an inspirational model for the kind of 
arena-rock experience they wanted their game Rock Band to convey.

\section{Music}

Since video games are audio-visual media, it is not surprising that music can be a way to convey, for example, the mood or the atmosphere in the game you design. In the article mentioned earlier Kyle Gabler, describes how a piece of music gave him the idea to Tower of Goo (the predecessor to World of Goo):

The idea behind Tower of Goo came up while I was listening to (for some reason) the opening to Astor Piazzolla's “Tango Apasionado" after walking home, and had this drizzly vision of a town at sunset where everyone was leaving their house, carrying out chairs, tables, and anything they could to build a giant tower in the center of their city. I didn't know why exactly, but they wanted to climb up and up and up - but they weren't very good civil engineers so you had to help them. [...] here's a case where an initial emotional target basically wrote the entire game.

\section{Prototypes and Vertical slice}

Prototypes are simple low fidelity models made during game development, to test or illustrate specific elements of the game. My respondents often mentioned prototypes, when they were describing the methods they used in designing and developing a game. Prototypes can be used for many purposes. Often the purpose is mainly "technical": that is, you want to test functionality, input devices, game mechanics or character movement in the game.

Buchenau \& Suri [2] propose a very wide operational definition of what they call experience prototyping:

[A]n Experience Prototype is any kind of representation, in any medium, that is designed to understand, explore or communicate what it might be like to engage with the product, space or system we are designing.

This definition of the concept seems to cover all the verbal and non-verbal ways to express and communicate the design vision that I have mentioned in this paper. My respondents expressed a narrower view of what a prototype is, more like the one Buchenau \& Suri say they want to focus on, namely "methods and techniques which support active participation”, and not representations that are communicated to a "mainly passive audience" [2].

At the end of the pre-production phase, a so called "vertical slice" is usually presented, before the developers get permission to enter the production phase. The vertical slice is a playable version of a small part of the game, including all essential features and assets in that part of the game. After the vertical slice is made, all the tools mentioned earlier for expressing and communicating the game vision become, more or less, redundant. Anyone who wants to understand the game concept, the gameplay and the "look and feel" of the game can just play the vertical slice.

\section{Spreading the Design vision}

As we have learned, there are many ways to express the design vision of the game-to-be. But how do game developers ensure that the team really takes in these expressions?

Since new team members enter the project every week, the design vision has to be explained again and again. The Lead designer at Dice told me that, when developing Mirror's Edge, they prepared a "starter packet" with different kinds of material explaining and illustrating the game concept. Such starter packets are presented at the kick-off, when a new phase starts, but can also be used when new members join the project at other points.

The senior producer at Dice offered this concise piece of advice concerning concept art, KAOF's and similar material:

Throw it up on the wall! Preferably close to the toilets or in the lunch room, where everybody sees it every day. Everyone in the team should "live" with the feeling of the game they are working with.

\section{CONCLUSIONS}

This paper states that there is a trend in game design - at least in some big companies - to use a player experience approach when designing and developing games. This approach, however, is not guided by studies of players' experience while playing games. Instead, it is primarily based on the designers' own experiences, which could be called autobiographical design. This could work well, as long as the designers make games for people who have the same taste and preferences as themselves. If they want to reach new target groups they might need to find other approaches or employ designers who belong to those target groups.

The intended player experience has to be communicated to everyone in the development team, and the developers I interviewed gave me examples of a wide variety of tools that can be used to express the kind of experience the game is supposed to mediate. One can use words, images, moving images, music and prototypes for that purpose.

In future studies I would like to find out how smaller studios and independent developers work with player experience. I also would like to know if there are different practices in game development in other parts of the world.

\section{REFERENCES}

1. Bateman, C. (Ed.) (2009). Beyond game design: nine steps towards creating better videogames. Boston, MA: Charles River Media/Cengage Technology.

2. Buchenau, M. \& Suri, J. F. (2000). Experience prototyping. In Proceedings of the 3rd conference on Designing interactive systems (DIS): processes, practices, methods, and techniques. New York, ACM Press. Pages: 424 - 433

3. Calleja, G. (2007). "Digital games as designed experience: reframing the concept of immersion", PhD Dissertation, Victoria University of Wellington, New Zealand, 2007. Available at http://www.gordoncalleja.com/GordonCalleja_Digital _Games_as_Designed_Experience.pdf 
4. de Kort Y. A. W., IJsselsteijn A. \& Gajadhar B. J. (2007) People, places, and play: A research framework for digital game experience in a sociospatial context In Selected Papers Proceedings of DiGRA 2007 Conference: Situated Play. Available at http://www.digra.org/dl/db/07311.21038.pdf [Retrived 2010-04-30]

5. Dewey, J. (1934). Art as experience. New York.

6. Ermi, L. \& Mäyrä, F. (2005). Fundamental components of the gameplay experience: Analysing immersion. In Selected Papers Proceedings of DiGRA 2005 Conference: Changing Views - Worlds in Play. Available at http://www.digra.org/dl/db/06276.41516.pdf [Retrived 2010-04-30]

7. Gámez, E. H. (2009). On the core elements of the experience of playing video games: Studying the gaming experience. Köln: Lambert Academic Publishing

8. Hagen, U. (2009). Where do game design ideas come from? Invention and recycling in games developed in Sweden. In Breaking new ground: Innovation in games, play, practice and theory. Proceedings of DiGRA 2009. http://www.digra.org/dl/db/09287.25072.pdf [2010-04-30]

9. Järvinen, A. (2008). Games without frontiers: methods for game studies and design. Tampere: Tampere University Press

10.Law, E. L-C., Vermeeren, A., Hassenzahl, M., \& Blythe, M. (Eds.) (2007). Proceedings of the workshop on Towards a UX Manifesto, in conjunction with HCI Conference, Lancaster, UK, 3rd Sept. 2007. Available at http://141.115.28.2/cost294/upload/506.pdf [2010-04-30]

11.Lazzaro, N. \& Keeker, K. (2004). What's my method? A game show on games. In CHI 2004, April 24-29, 2004, Vienna, Austria. ACM 1-58113-703$6 / 04 / 0004$.

12. McCarthy, J. \& Wright, P. (2004). Technology as experience. Cambridge, Mass.: MIT Press
13. Mills, T. (2003). Experience design: It's not just for Disneyland anymore. Available at Mills' personal web site: http://www.inajar.org/other/experience.pdf [2010-04-30]

14. Mäyrä, F. (2007). The contextual game experience: On the socio-culture contexts for meaning in digital play. In Selected Papers Proceedings of DiGRA 2007 Conference: Situated Play. Available at http://www.digra.org/dl/db/07311.12595.pdf [2010-04-30]

15. Norman, D. A. (2004). Emotional design: why we love (or hate) everyday things. New York: Basic Books.

16. Oppelaar, E-J. R.G., Hennipman, E-J., van der Veer, G. C. (2008). Experience design for dummies. Procedings at ECCE'08, September 16-19, 2008, Madeira, Portugal. ACM 978-1-60558-399-0/08/09.

17. Pine, B. J. \& Gilmore, J. H. (1998). Welcome to the experience economy. Harvard Business Review, JulyAugust 1998. Reprint 98407 Available at http://www.itu.dk/courses/DIDE/E2006/downloads/welcom e_to_the_experience_economy.pdf [2010-04-30]

18. Rouse, R. (2005). Game design: theory \& practice. (2. ed.) Plano, Tex.: Wordware.

19. Schell, J. (2008). The art of game design: a book of lenses. Amsterdam: Elsevier/Morgan Kaufmann.

20. Sengers, P. (2006) Autobiographical design. Paper presented at the experience-centred design workshop. In Ext. Abstracts, CHI 2006, ACM Press (2006), 1691-1694. Available at http://www-users.cs.york.ac.uk/ mblythe/CHI/Sengers.pdf [2010-04-30]

21. Swink, S. (2009). Game feel: a game designer's guide to virtual sensation. Amsterdam: Morgan Kaufmann Publishers/Elsevier.

22. Sykes, J. \& Federoff, M. (2006) Player-centred game design. In CHI 2006, April 22-27, 2006, Montreal, Quebec, Canada. ACM 1-59593-298-4/06/000 